\title{
Vitamin D and Vulnerable Carotid Plaque
}

\author{
(D).S. McNally, (DT.M. Burton, (D)B.W. Aldred, (D).-E. Kim, (DM.S. McLaughlin, (DL.B. Eisenmenger, (DG.J. Stoddard, (D).J. Majersik,
} D.V. Miller, (D) G.S. Treiman, and DD.L. Parker

\begin{abstract}
BACKGROUND AND PURPOSE: MR imaging-detected carotid intraplaque hemorrhage indicates vulnerable plaque with high stroke risk. Angiotensin II stimulates intraplaque hemorrhage in animal models, and the angiotensin system is highly regulated by vitamin D. Our purpose was to determine whether low vitamin D levels predict carotid intraplaque hemorrhage in humans.
\end{abstract}

MATERIALS AND METHODS: In this cross-sectional study, 65 patients with carotid disease underwent carotid MR imaging and blood draw. Systemic clinical confounders and local lumen imaging markers were recorded. To determine the association of low vitamin $D$ levels with MR imaging detected intraplaque hemorrhage, we performed multivariable Poisson regression by using generalized estimating equations to account for up to 2 carotid arteries per patient and backward elimination of confounders. MR imaging detected intraplaque hemorrhage volume was also correlated with vitamin D levels and maximum plaque thickness. Thirty-five patients underwent carotid endarterectomy, and histology-detected intraplaque hemorrhage was correlated with vitamin $\mathrm{D}$ levels and total plaque area.

RESULTS: Low vitamin D levels $(<30 \mathrm{ng} / \mathrm{mL}$, prevalence ratio $=2.05, P=.03$ ) were a significant predictor of MR imaging detected intraplaque hemorrhage, along with plaque thickness (prevalence ratio $=1.40, P<.001$ ). MR imaging detected intraplaque hemorrhage volume linearly correlated with plaque thickness (partial $r=0.45, P<.001$ ) and low vitamin D levels (partial $r=0.26, P=.003$ ). Additionally, histology-detected intraplaque hemorrhage area linearly correlated with plaque area (partial $r=0.46, P<.001$ ) and low vitamin $D$ levels (partial $r=0.22, P=.03$ ). The association of intraplaque hemorrhage volume with low vitamin $D$ levels was also higher with ischemic stroke.

CONCLUSIONS: Low vitamin D levels and plaque thickness predict carotid intraplaque hemorrhage and outperform lumen markers of vulnerable plaque. This research demonstrates a significant link between low vitamin D levels and carotid intraplaque hemorrhage.

ABBREVIATIONS: ATIR = angiotensin II type 1 receptor; IPH = intraplaque hemorrhage; $\mathrm{NADPH}=$ nicotinamide adenine dinucleotide phosphate; $\mathrm{PR}=$ prevalence ratio

arge-artery atherosclerosis, including carotid disease, is a sig-

nificant cause of ischemic stroke and an important therapeutic target. ${ }^{1}$ Reports estimate that carotid disease accounts for $10 \%-$ $15 \%$ of ischemic strokes. ${ }^{2,3}$ Additionally, recurrent stroke is more highly associated with carotid atherosclerosis than other causes. ${ }^{4,5}$

Received November 6, 2015; accepted after revision April 26, 2016.

From the Department of Radiology and Imaging Sciences, Utah Center for Advanced Imaging Research (J.S.M., B.W.A., S.-E.K., M.S.M., L.B.E., D.L.P.); Department of Neurology (T.M.B., J.J.M.); Department of Orthopedics, Study Design and Biostatistics Center (G.J.S); Department of Pathology (D.V.M.); and Department of Surgery at the University of Utah and VA Salt Lake City Health Care System, Salt Lake City, Utah (G.S.T.)

This work was supported by a Radiological Society of North America Research Scholar Grant; a University of Utah Intramural Seed Grant; and a grant for the Study Design and Biostatistics Center, with funding, in part, from the National Center for Research Resources and the National Center for Advancing Translational Sciences, National Institutes of Health, grant 8ULITR000105 (formerly ULIRR025764).

Paper previously presented at: Annual Meeting of the American Society of Neuroradiology and the Foundation of the ASNR Symposium, April 25-30, 2015; Chicago, Illinois.
While only $10 \%-15 \%$ of patients with stroke have large-artery atherosclerosis, approximately one-third of early recurrence occurs in this group. ${ }^{6,7}$

These past estimates are based on whether moderate or severe stenosis is present, defined for the carotid arteries as NASCET stenosis of $>50 \% .{ }^{8}$ More recent studies have questioned stenosis, finding that other markers predict unstable plaque better, including intraplaque hemorrhage (IPH). Carotid IPH is a better estimate of recurrent stroke risk, with a $\sim 5$-fold higher risk of recurrent stroke in all stenosis categories in multiple recent studies and meta-analyses. ${ }^{9-11}$ Carotid IPH can be accurately detected with heavily T1-weighted sequences, including MPRAGE. Both

Please address correspondence to J. Scott McNally, MD, PhD, University of Utah, Department of Radiology and Imaging Sciences, 30 North 1900 East \#1A071, Salt Lake City, UT 84132-2140; e-mail: scott.mcnally@hsc.utah.edu

- Indicates open access to non-subscribers at www.ajnr.org

三 Indicates article with supplemental on-line table.

http://dx.doi.org/10.3174/ajnr.A4849 
MPRAGE and TOF have low false-negative rates (3\% versus 4\%), but the MPRAGE sequence has a lower false-positive rate $(20 \%)$ compared with TOF (44\%). ${ }^{12}$

Despite MR imaging detection of IPH, no treatment has been shown to reverse these lesions. A potential treatment target is the angiotensin system, a major determinant of carotid plaque instability and stroke risk. ${ }^{13}$ Angiotensin II stimulates adventitial neovascularity and is implicated in animal models of IPH. ${ }^{14}$ Angiotensin II increases plaque microvessel angiogenesis through the endothelial angiotensin II type 1 receptor (AT1R). ${ }^{15}$ AT1R activation leads to reactive oxygen species formation through the nicotinamide adenine dinucleotide phosphate (NADPH) oxidase and plaque inflammation. ${ }^{15}$ Extrapolating from this, inhibition of the angiotensin system may prevent or decrease IPH.

The angiotensin system is highly regulated by an endogenous inhibitory axis, including vitamin $\mathrm{D}$ and the vitamin $\mathrm{D}$ receptor. ${ }^{16}$ The vitamin $\mathrm{D}$ receptor is downregulated in atherosclerotic plaque in animal models. ${ }^{17}$ Vitamin $\mathrm{D}$ deficiency has been associated with increased intima-media and plaque thickness in subclinical carotid atherosclerosis. ${ }^{18}$ Serum vitamin D levels are negatively correlated with carotid intima-media thickness $(r=$ -0.51). ${ }^{19}$ Prior studies have demonstrated a high prevalence of vitamin $\mathrm{D}$ insufficiency $(<30 \mathrm{ng} / \mathrm{mL}, 63.6 \%)$ and increased stroke risk in the Mountain West population of the United States. ${ }^{20}$ This mirrors the prevalence of vitamin D deficiency $(<20 \mathrm{ng} / \mathrm{mL})$ in the United States as a whole $(41.6 \%) .^{21}$

Our purpose was to determine whether low vitamin D levels predict carotid IPH in patients with carotid disease. Our hypothesis was that low vitamin D levels are associated with carotid IPH when controlling for systemic and local plaque confounders. If confirmed, this pathway may represent an important treatment target in patients with carotid IPH.

\section{MATERIALS AND METHODS \\ Clinical Study Design}

This was a cross-sectional study of patients with carotid disease, defined as $\geq 2$-mm-thick carotid plaque. Patients were consecutively recruited from neurovascular outpatient and inpatient services. Exclusions included patients younger than 18 years of age, prisoners, pregnancy, or those with contraindications to MR imaging (eg, pacemakers). There were no exclusion/inclusion criteria for carotid stenosis other than complete occlusion. Sixty-five patients were recruited and completed carotid MR imaging and blood draw.

Ethics. Institutional review board approval was obtained along with informed consent from all subjects. In subjects with impaired decisional capacity, legal authorized representative consent and patient assent was obtained.

\section{Serologic Analysis of Vitamin D and Angiotensin II}

All patients underwent blood draw following IV placement for MR imaging. Samples were taken directly to the Associated Regional and University Pathologists for serum vitamin D analysis by quantitative high-performance liquid chromatography tandem mass spectrometry (25-hydroxyvitamin $\mathrm{D}_{2}$ and $\mathrm{D}_{3}$; http:// ltd.aruplab.com/Tests/Pub/2002348) and plasma angiotensin II analysis by quantitative immunoassay (http://ltd.aruplab.com/
Tests/Pub/0098771). Vitamin D levels were considered low/insufficient at $<30 \mathrm{ng} / \mathrm{mL}$. Angiotensin II levels were considered high at $>18 \mathrm{ng} / \mathrm{L}$.

\section{Research MR Imaging Protocol}

Images were obtained on 3T MR imaging scanners (Trio, Verio, Skyra and Prisma scanners; Siemens, Erlangen, Germany) with custom-made carotid coils. ${ }^{22}$ Each MR imaging included brain DWI and carotid MPRAGE sequences acquired with custom neck coils described below.

\section{Subject-Specific Radiofrequency Coils}

A modular system of subject-specific radiofrequency coil arrays was used to maximize signal to noise. ${ }^{23}$ The head coil provides head immobilization, essential to carotid imaging. ${ }^{24}$ Either 7-channel or 9-channel coils were used, connected to preamplifiers through low-resistance connectors, allowing them to be interchanged to fit necks of different shapes and sizes. These coils can image simultaneously with clinical head coils without extra positioning hardware.

\section{Carotid MPRAGE and IPH Determination}

MPRAGE parameters were the following: 3D, TR/TE/TI $=6.39$ / $2.37 / 370 \mathrm{~ms}$, flip angle $=15^{\circ}, \mathrm{FOV}=130 \times 130 \times 48 \mathrm{~mm}^{3}$, matrix $=256 \times 256 \times 48$, voxel $=0.5 \times 0.5 \times 1.0 \mathrm{~mm}^{3}$, fat saturation, acquisition time $=\sim 5$ minutes as described previously. ${ }^{25}$ Images were obtained from $20 \mathrm{~mm}$ below to $20 \mathrm{~mm}$ above the carotid bifurcation at a $1.0-\mathrm{mm}$ section thickness. Carotid IPH was defined by MPRAGE-positive plaque with $\geq 2$-fold signal compared with the sternocleidomastoid muscle (Fig 1). ${ }^{26}$ We have previously shown that MPRAGE-positive plaque corresponds to carotid IPH on histology. ${ }^{26}$ IPH volume was determined quantitatively with volumes traced from the PACS.

\section{Carotid Lumen Measurements}

All non-IPH carotid lumen measurements were determined by consensus of 2 reviewers, blinded to brain MR imaging and clinical covariates. The entire carotid plaque was considered 1 unit, from $20 \mathrm{~mm}$ above to $20 \mathrm{~mm}$ below the bifurcation. Maximum plaque thickness was measured in the transverse plane on MPRAGE images, perpendicular to the center axis of the lumen (Fig 1). Lumen markers (stenosis, ulceration, and intraluminal thrombus) were determined from noncontrast TOF with parameters as follows: $3 \mathrm{D}, \mathrm{TR} / \mathrm{TE}=25 / 4.02 \mathrm{~ms}$, flip angle $=20^{\circ}, \mathrm{FOV}=$ $160 \times 160 \times 90 \mathrm{~mm}$, matrix $=256 \times 256$, section thickness $=$ $0.64 \mathrm{~mm}, 144$ sections, acquisition time $=\sim 3.5$ minutes. In all cases, duplex sonography was performed before study entry and was used as a complementary measure of stenosis. In cases of $>70 \%$ stenosis by either TOF or sonography or when stenosis measurements disagreed, lumen stenosis was confirmed by using contrast CTA or MRA. The percent diameter stenosis was determined with NASCET criteria, with a submillimeter measurement tool and $[(a-b) / a] \times 100 \%$, where $b$ is the diameter of maximal stenosis and $a$ is the diameter of the ICA distal to the stenosis (Fig 1). ${ }^{27-29}$ Multivariable regression was performed by using both NASCET and millimeter stenosis $(b)$, first described on CTA. ${ }^{30}$ No near-occlusions were found in this dataset, as de- 


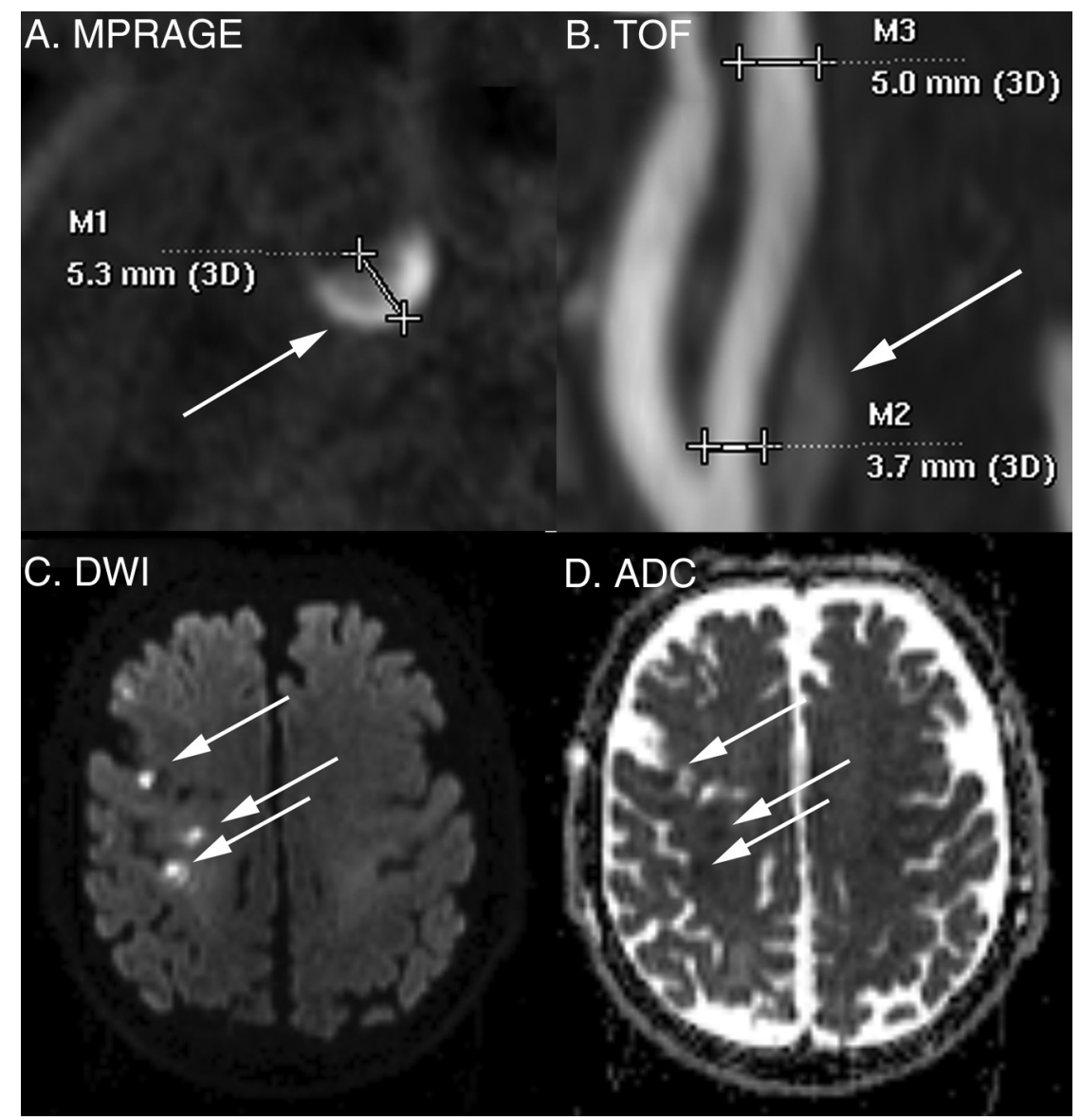

FIG 1. Carotid and brain MR imaging. Carotid IPH and maximum plaque thickness were detected by using the MPRAGE sequence as shown in this representative image with right-sided carotid IPH (A). 3D TOF MRA was used alongside duplex sonography in all patients to determine lumen findings, as in this subject with $26 \%$ stenosis by NASCET criteria (B). Stroke was determined by using the American Heart Association criteria supplemented with DWI, as in this example with recent right MCA distribution infarcts $(C$ and $D)$.

fined by visible bulb stenosis, a distal ICA diameter of $\leq 3 \mathrm{~mm}$, and a distal ICA/distal external carotid artery ratio of $\leq 1.25 .{ }^{29,30}$ Ulceration was determined by using a size threshold of 2 $\mathrm{mm} \cdot{ }^{31}$ Intraluminal thrombus was determined by a filling defect and confirmed in all cases with contrast CTA or MRA. ${ }^{32}$

\section{Ischemic Stroke Determination}

Ischemic stroke was determined by using the American Heart Association definition of CNS infarction: brain or retinal cell death attributable to ischemia based on the following: 1) imaging evidence of cerebral or retinal ischemia in the carotid distribution, or 2) clinical symptoms persisting for $\geq 24$ hours, with other etiologies excluded. ${ }^{33}$ We reviewed neurovascular clinic or inpatient charts to determine the presence of recent stroke occurring at the time of recruitment. Asymptomatic ("silent") recent infarcts were included as strokes and determined on brain DWI performed in all patients to supplement clinical determination of infarct by showing acuity and distribution (Fig 1). DWI-positive carotid territory infarcts were detected using DTI trace images, which are superior to conventional DWI in detecting recent infarcts. ${ }^{34,35}$ The DTI parameters were 2D, $128 \times 128$ matrix, 3-mm section thickness, $b=2000,20$ directions. Brain DWI was interpreted by a Certificate of Added qualification-certified neuroradiologist.

\section{Clinical Characteristics}

Clinical characteristics were determined by chart review, including cerebrovascular risk factors of age, male sex, diabetes, hypertension, hyperlipidemia, renal insufficiency, body mass index, and smoking status. We recorded the following cerebrovascular medications: antiplatelets, anticoagulants, statins, and antihypertensives, including antiangiotensin medications: angiotensin-converting enzyme inhibitors and angiotensin receptor blockers.

\section{Histologic Processing}

In 35 patients who underwent carotid endarterectomy, each specimen was fixed in $10 \%$ neutral buffered formalin for histology. The ratio of the fixative to the specimen was at least 10:1. Specimens were decalcified in 1\% Enhanced Decalcification Formulation (SL85-32; Statlab, Lewisville, Texas). Tissue cassettes were processed on an automated Vacuum Infiltrating Processor (Sakura, Alphen aan den Rijn, the Netherlands), embedded in paraffin wax, sectioned at 3- to 4-mm intervals, and stained with hematoxylin-eosin.

\section{Histology Interpretation of IPH}

A pathologist outlined recent IPH by using hematoxylin-eosin, blinded to MPRAGE results. "Recent" IPH was defined by intact red blood cells or degenerated red blood cells on hematoxylin-eosin. Each carotid area positive for IPH was then compared with vitamin D levels.

\section{Statistical Analysis}

Statistical modeling was performed by using generalized estimating equations to account for data clustering, with up to 2 carotid arteries per patient. Carotid arteries were treated as separate units grouped within subjects because IPH may be associated with local carotid plaque markers (eg, plaque thickness) and systemic clinical factors (eg, age). Because $>1$ marker for IPH was being studied, potential confounding was investigated on the outcome variable, IPH. Therefore only 1 data table was required with $P$ values from univariable generalized estimating equation Poisson regression models. Poisson regression directly estimates the prevalence ratio $(\mathrm{PR})$, which is more intuitive to interpret than an odds ratio from a logistic regression approach (Zou and Donner ${ }^{36}$ ). Next, all potential confounders with $P<.20$ from a univariable model were placed in an initial multivariable generalized estimating equation Poisson regression model for IPH, then eliminated in a backward fashion until all remaining variables met the threshold $P<.10$. A liberal significance criterion, $P<.10$, was used to protect against residual confounding (Maldonado and Greenland ${ }^{37}$ ). 
Table 1: Final MRI-IPH prediction model ${ }^{a}$

\begin{tabular}{lccc}
\hline \multicolumn{1}{c}{ Carotid IPH Predictor } & PR & P Value & $\mathbf{9 5 \% ~ C l}$ \\
\hline Maximum plaque thickness, per l-mm increase & 1.40 & $<.001$ & $1.18-1.67$ \\
Low vitamin D level of $<30 \mathrm{ng} / \mathrm{mL}$, low versus high & 2.05 & .03 & $1.06-3.96$ \\
\hline
\end{tabular}

${ }^{a}$ The final prediction model for the presence of MRI-detected carotid IPH depended on 2 factors: maximum plaque thickness and low vitamin D levels.

Table 2: IPH prediction model with angiotensin system confounders ${ }^{\mathrm{a}}$

\begin{tabular}{lccc}
\multicolumn{1}{c}{ Carotid IPH Predictor } & PR & $\boldsymbol{P}$ Value & $\mathbf{9 5 \%} \mathbf{C l}$ \\
\hline Maximum plaque thickness, per 1-mm increase & 1.40 & $<.001$ & $1.18-1.67$ \\
Low vitamin D level, <30 ng/mL, low versus high & 2.07 & .04 & $1.05-4.09$ \\
Angiotensin II level (ng/L), per 1-U increase & 1.00 & .80 & $0.99-1.01$ \\
ACE inhibitor use & 1.05 & .87 & $0.56-1.99$ \\
ARB use & 0.93 & .90 & $0.31-2.77$ \\
\hline
\end{tabular}

Note:-ARB indicates angiotensin receptor blockers.

a To illustrate the lack of confounding, we included markers of systemic angiotensin activity, including angiotensin II, ACE inhibitor use, and ARB use in addition to our final model of maximum plaque thickness and low vitamin D levels.

For hypothesis testing of markers predictive of IPH, we used the traditional $P<.05$. In binary outcome models, 5 outcome events for every predictor variable are sufficient to avoid overfitting. ${ }^{38}$ With 48 carotid plaques positive for IPH and 80 negative for IPH, $48 / 5$ or 9.6 or up to 9 predictor variables could be included in the model without overfitting, exceeding the number of variables in our final model. Additionally, we identified the following potential confounders with a scientific basis for confounding the association between vitamin D and IPH: angiotensin, angiotensin-converting enzyme inhibitor use, and angiotensin receptor blocker use. Because of the high potential for these to confound the vitamin D and IPH association, we used a combination of the $10 \%$ change in estimate and backward elimination and kept these potential confounders in a secondary analysis even though they were eliminated in the primary analysis. We also calculated IPH volume as a continuous variable and used a linear mixed-effects regression model to correlate carotid IPH with maximum plaque thickness and vitamin D levels, again accounting for up to 2 carotid arteries per patient. For the histologyoutlined IPH area correlation with vitamin D levels, a random intercept linear regression model was used with an autoregressive correlation structure repeated-measures analysis of the 35 subjects that had underwent carotid endarterectomy. In this analysis, the "time" repetition variable was each histology slide, and the "group" variable was each carotid plaque. All statistical analyses were performed with STATA 13.1 (StataCorp, College Station, Texas).

\section{RESULTS}

\section{Clinical Characteristics}

Sixty-five patients were recruited, with a mean age $72.3 \pm 8.3$ years, $90.8 \%$ men and $3.1 \%$ minorities. Patients had multiple cerebrovascular risk factors $(69.2 \%$ current or prior smokers, $87.7 \%$ hypertensive, $84.6 \%$ hyperlipidemic, $44.6 \%$ diabetic) and were aggressively managed before enrollment $(84.6 \%$ on antihypertensives, $89.2 \%$ on statins, $81.5 \%$ on antiplatelets) (On-line Table). These characteristics reflect the high prevalence of carotid disease in our population.

\section{Imaging and Clinical Characteristics by Vessel}

Imaging and clinical characteristics were also listed by vessel and broken down by IPH status (positive versus negative) in the On- line Table. Each patient contributed 2 carotid plaques, with the exception of 2 carotid occlusions that were excluded, leaving 128 carotid arteries for the final sample. Stenosis was worse in carotid arteries with IPH-positive versus negative plaque (NASCET stenosis of $53.9 \%$ versus $35.7 \%$ and millimeter stenosis of 2.25 versus $3.17 \mathrm{~mm}, P=.003)$. Maximum plaque thickness was also higher (5.53 versus $4.08 \mathrm{~mm}, P<.001$ ), and there was a higher prevalence of ulceration (64.6\% versus $37.5 \%, P=.02)$ and intraluminal thrombus, though rare (6.3\% versus $0.0 \%, P=.05)$. Some factors were potential confounders between IPH-positive and negative status $(P<.20)$, requiring multivariable regression to determine essential IPH predictors.

\section{Multivariable Generalized Estimating Equation Poisson Regression Analysis for Carotid IPH Prediction}

Multivariable generalized estimating equation Poisson regression analysis was performed to determine predictors of carotid IPH from the On-line Table. The initial model included 9 predictors with $P<.20$ : NASCET stenosis, millimeter stenosis, maximum plaque thickness, ulceration, intraluminal thrombus, high angiotensin II (>18 ng/L), vitamin D level ng/mL (continuous variable), low vitamin D level $(<30 \mathrm{ng} / \mathrm{mL})$, and male sex. Table 1 shows the final model after sequential backward elimination of confounders with $P>.10$. The final model included maximum plaque thickness $(\mathrm{PR}=1.40 ; 95 \% \mathrm{CI}, 1.18-1.67 ; P<.001)$ and low vitamin D levels ( $\mathrm{PR}=2.05 ; 95 \% \mathrm{CI}, 1.06-3.96 ; P=.03$ ) as significant predictors of carotid IPH. Table 2 illustrates the lack of confounding by angiotensin II, angiotensin-converting enzyme inhibitor, and angiotensin receptor blockers use.

\section{Linear Mixed-Effects Regression Model of IPH Volume with Maximum Plaque Thickness and Low Vitamin D Levels}

Carotid IPH volume significantly correlated with maximum plaque thickness $(r=0.45, P<.001)$ and low vitamin D levels $(r=0.26, P=$ .003 ) as depicted in the linear regression plot (Fig 2).

\section{Carotid IPH Histology and Vitamin D Levels}

Histology-defined IPH area (Fig 3A) negatively correlated with vitamin D levels (Fig $3 B$ ). In addition, IPH area correlated with plaque area (partial $r=0.46, P<.001$ ) and low-versus-normal vitamin D levels (partial $r=0.22, P=.03$ ) (Fig 3C).

\section{Carotid IPH, Vitamin D Levels, and Stroke}

IPH volume more negatively correlated with vitamin D levels with ischemic stroke (hollow squares, thick dashed line, partial $r=$ $-0.21, P=.27$ ) compared to without it (solid circles, thick solid line, partial $r=-0.06, P=.53$ ) (Fig $4 A$ ). Vitamin D levels were also lower in patients with versus without stroke in the setting of IPH-negative plaque (mean, $33.5 \pm 13.2 \mathrm{ng} / \mathrm{mL}$ in 73 carotids versus $26.2 \pm 17.4 \mathrm{ng} / \mathrm{mL}$ in 7 carotids, $P=.17)$ and less so with IPH-positive plaque $(27.8 \pm 12.6 \mathrm{ng} / \mathrm{mL}$ in 25 carotids versus $25.6 \pm 11.1 \mathrm{ng} / \mathrm{mL}$ in 23 carotids, $P=.51$ ) (Fig $4 B$ ).

AJNR Am J Neuroradiol 37:2092-99 Nov 2016 www.ajnr.org 

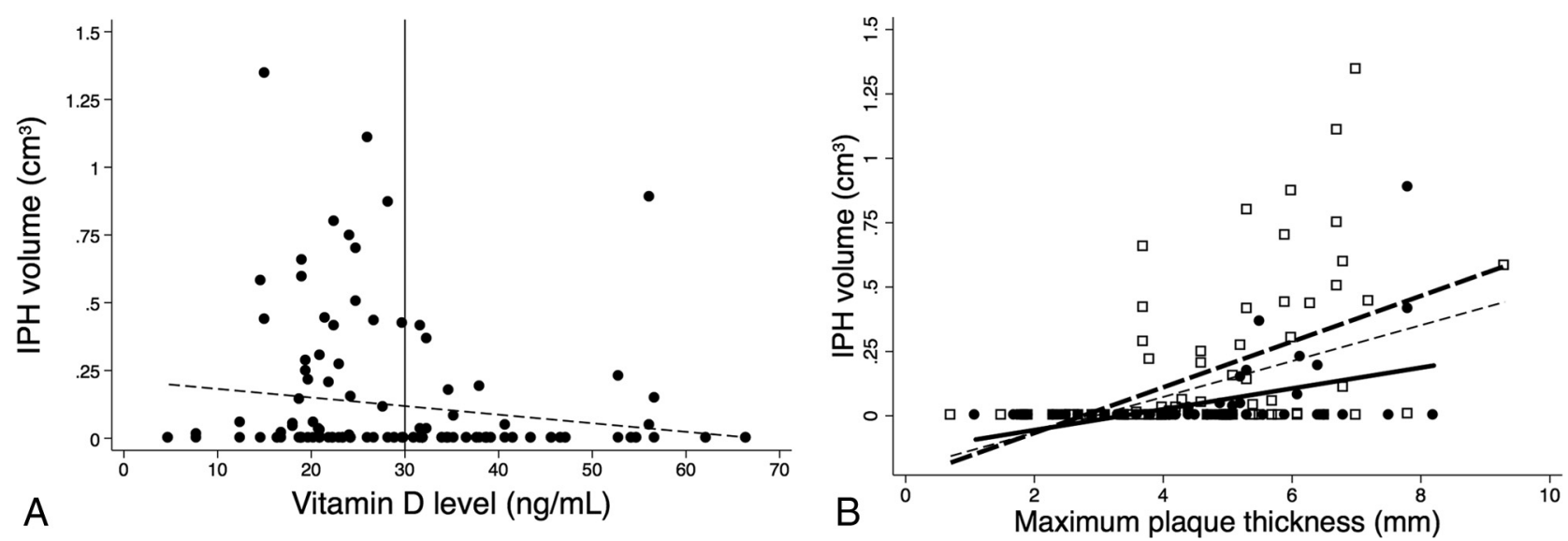

FIG 2. Linear regression of MR imaging-detected IPH volume, plaque thickness, and vitamin D status. Pooled data demonstrate the IPH volume negative correlation with vitamin $D$ level $(A)$ and correlation with maximal plaque thickness (partial $r=0.45, P<.001$, thin dashed line) and low-versus-normal vitamin D levels (partial $r=0.26, P=.003$; low vitamin D level: empty squares and thick dashed line; normal vitamin $D$ levels: solid circles and thick solid line, B).
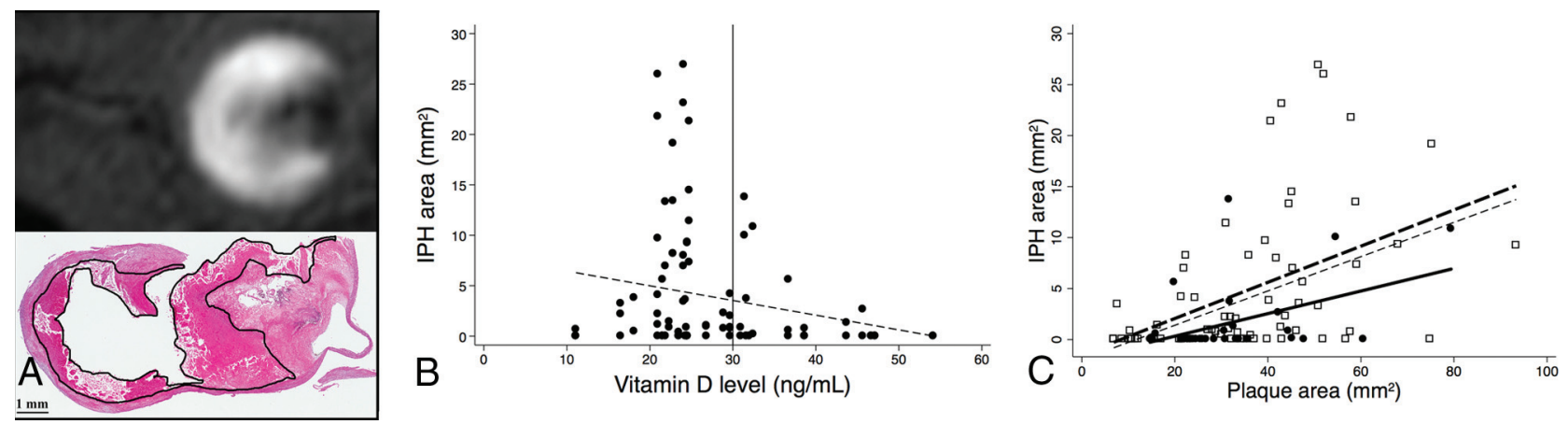

FIG 3. Linear regression of IPH area on histology, plaque area, and vitamin D status. Representative MPRAGE-positive plaque (upper image) and $\mathrm{IPH}$ area outlined on the corresponding hematoxylin-eosin stain (lower image) (A). Pooled data demonstrate the IPH area negatively correlating with vitamin $D$ levels $(B)$ and positively correlating with plaque area (partial $r=0.46, P<.001$, thin dashed line) and low-versus-normal vitamin $D$ levels (partial $r=0.22, P=.03$, low vitamin D level: empty squares and thick dashed line; normal vitamin D level: solid circles and thick solid line) (C).
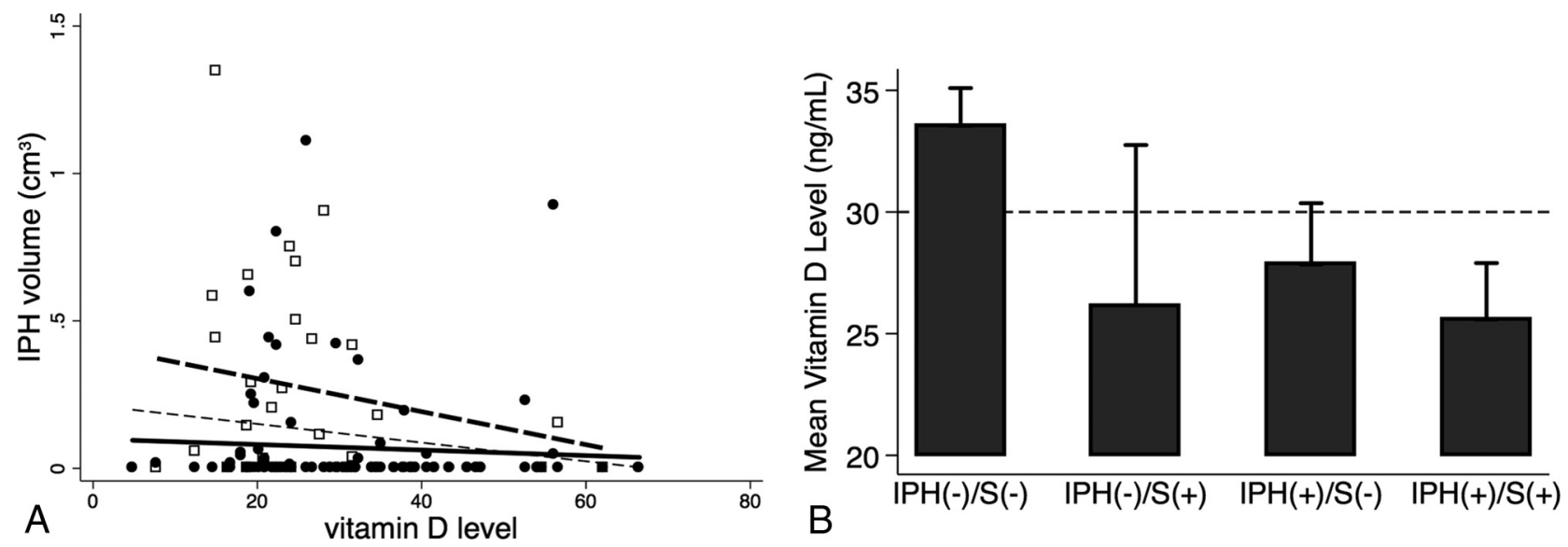

FIG 4. Association of IPH volume, vitamin D levels, and ischemic stroke. IPH volume was negatively correlated with vitamin D levels as in Fig $2 A$ (thin dashed line). When stratified by ischemic stroke status, IPH volume was more negatively correlated with vitamin D levels (hollow squares, thick dashed line, partial $r=-0.21, P=.27$ ) in ischemic stroke compared to without it (solid circles, thick solid line, partial $r=-0.06, P=.53$ ) (A). Vitamin D levels were also lower in groups positive-versus-negative for stroke in the setting of IPH-negative plaque $(\mathrm{mean}, 33.5 \pm 13.2 \mathrm{ng} / \mathrm{mL}$ in 73 carotids versus $26.2 \pm 17.4 \mathrm{ng} / \mathrm{mL}$ in 7 carotids, $P=.17)$ and less so in the setting of IPH-positive plaque $(27.8 \pm 12.6 \mathrm{ng} / \mathrm{mL}$ in $25 \mathrm{carotid}$ arteries versus $25.6 \pm 11.1 \mathrm{ng} / \mathrm{mL}$ in 23 carotid arteries, $P=.51)(B) . S$ indicates carotid territory ischemic stroke status (positive or negative).

\section{Carotid IPH Volume Follow-Up}

Two patients were re-evaluated after 1 year (Fig 5). Both were treated with medical therapy (statins, antiplatelets, and anti- hypertensives) and both patients' primary care physicians were alerted to low vitamin D levels $(<30 \mathrm{ng} / \mathrm{mL})$. Patient 1 was supplemented, vitamin D increased (baseline/1 year: 18.1/26.8 

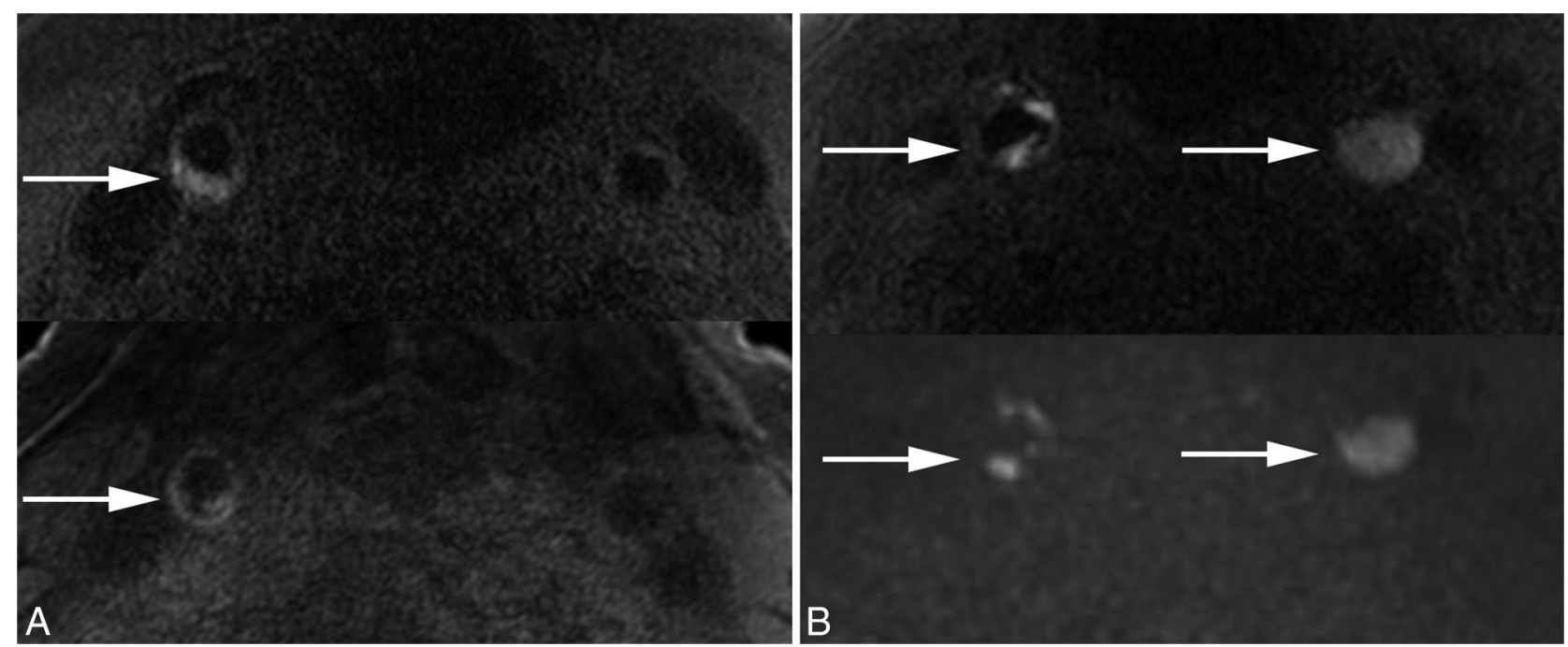

FIG 5. Vitamin D supplementation and follow-up. A, Patient 1: Baseline (upper arrow) versus 1-year follow-up (lower arrow) with vitamin D supplementation and medical therapy, including statins and antiplatelet and antihypertensive medications, demonstrates decreased IPH volume in a patient with no interval stroke (vitamin D baseline/1 year: 18.1/26.8 ng/mL; carotid IPH baseline/1 year: $0.151 / 0.115 \mathrm{~cm}^{3}$, or $24.1 \%$ decreased IPH volume). The patient remained asymptomatic in the year between the 2 scans. B, Patient 2: Baseline (upper arrow) versus 1-year follow-up (lower arrow) without vitamin D supplementation but with medical therapy, including statins and antiplatelet and antihypertensive medications, demonstrates minimally changed IPH volume (vitamin D baseline/1 year: 20.9/10.7 ng/mL; carotid IPH baseline/1 year: 1.041/0.996 $\mathrm{cm}^{3}$, or $4.3 \%$ decreased IPH volume). In addition, this patient had bilateral strokes in the year between the 2 scans.

$\mathrm{ng} / \mathrm{mL}$ ), carotid IPH volume decreased by $24.1 \%$ (baseline/1 year: $0.151 / 0.115 \mathrm{~cm}^{3}$ ), and he remained asymptomatic. Patient 2 was not supplemented, vitamin D levels decreased (baseline/1 year: 20.9/10.7 ng/mL), carotid IPH volume minimally decreased by $4.3 \%$ (baseline/1 year: $1.041 / 0.996 \mathrm{~cm}^{3}$ ), and he had sequential bilateral strokes.

\section{DISCUSSION}

This work shows that both the presence and volume of carotid IPH are strongly associated with plaque thickness and low vitamin D levels, and not necessarily with percentage stenosis or other measures of carotid architecture. This finding supports the idea that low vitamin D levels may play a role in atherosclerosis and stroke risk. Considering its multiple health benefits, vitamin D testing may be worthwhile in patients with vulnerable carotid plaque.

Low vitamin D levels have been linked to cardiovascular disease in many prior studies. ${ }^{39}$ Two cohort studies evaluating participants in the Framingham Heart Study (Offspring Cohort) and the Copenhagen City Heart Study found increased risk of ischemic stroke with lower vitamin D levels, ${ }^{40,41}$ and a low vitamin D level is an independent predictor of ischemic stroke volume. ${ }^{42}$ Most important, vitamin D supplementation decreases muscle atrophy, falls, hip fractures, and cognitive impairment and leads to functional improvement in patients with stroke. ${ }^{43,44}$ Vitamin $\mathrm{D}$ also has many direct beneficial effects on the vasculature. Within 1 minute of treatment, vitamin D increases endothelial cell nitric oxide production. ${ }^{45}$ Active vitamin D also improves endothelial function by decreasing AT1R and NADPH oxidase expression and increasing superoxide dismutase expression. ${ }^{46}$

An intriguing possibility is that low vitamin D levels may allow disinhibition of the local angiotensin system, leading to microvessel leakage of blood products. Alternatively, vitamin
D may have an effect on the lipid-rich necrotic core where microhemorrhages occur. Most interesting, while statins have been shown to decrease the carotid lipid-rich necrotic core ${ }^{47}$ and decrease plaque inflammation, ${ }^{48}$ statins do not ensure plaque stabilization. In trials in patients with IPH, including those with symptomatic low-grade $(<50 \%)$ carotid stenosis, there is an extremely high stroke recurrence rate $(46.0 \%$ per patient-year), despite aggressive therapy with statins, aspirin, and antihypertensives. ${ }^{49}$ Most interesting, supplementing with vitamin $\mathrm{D}$ allows most statin-intolerant patients to tolerate statins and reach current low-density lipoprotein targets. ${ }^{50}$ This finding suggests an interaction between statins and vitamin $\mathrm{D}$, and optimizing both may be important in treating patients with carotid IPH.

One limitation of our study is its cross-sectional nature, making it difficult to determine causation between low vitamin $\mathrm{D}$ levels and carotid IPH. Another limitation is that unknown confounders may exist that we did not have data to control for in the regression analysis. These would include variables related to both predictor (vitamin D) and outcome (IPH). While we evaluated multiple factors that may influence both vitamin $\mathrm{D}$ levels and carotid IPH, including age, sex, body mass index, angiotensin system markers, and carotid markers including plaque thickness, we did not find a significant association between IPH and any of the factors listed except for plaque thickness. Still, it is possible that low vitamin D levels are linked to some other undiscovered confounder or sedentary lifestyle, which even surveys may fail to appropriately quantify. ${ }^{51}$ Finally, our study recruited patients from the neurovascular clinic and inpatient settings who were predominantly overweight (average body mass index $=28.6$ ), white (97\%), and men (91\%) and should be applied primarily to that population. Still, low vitamin D levels are highly prevalent in African American and Hispanic populations, and given the higher AJNR Am J Neuroradiol 37:2092-99 Nov 2016 www.ajnr.org 
rates of stroke and heart attack in these groups, further study in such minorities would be worthwhile.

Despite these limitations, in patients with carotid IPH, vitamin D screening and supplementation may be warranted. A trial of vitamin $\mathrm{D}$ supplementation in patients with carotid disease with low vitamin D levels could clarify whether vitamin D reduces or prevents IPH. Randomized controlled clinical trials may be warranted to determine the effect of vitamin D on preventing or reversing carotid IPH and its influence on future stroke risk. The relationship between vitamin D levels and IPH could be further investigated in animal models, including the apolipoprotein $E$ knockout mouse model of atherogenesis coupled with vitamin D deficiency or vitamin D receptor knockout models.

\section{CONCLUSIONS}

Vitamin D insufficiency was associated with both the presence and volume of carotid IPH in patients with carotid atherosclerosis. These results link low vitamin D levels with plaque vulnerability. Future clinical trials are needed to determine whether vitamin D supplementation can decrease IPH and subsequent stroke risk. Animal studies may also allow further insight into the role of vitamin D and receptor status in pathways leading to IPH.

Disclosures: Statistical analysis for this study was supported by the Study Design and Biostatistics Center grant* with funding in part from the National Center for Research Resources and the National Center for Advancing Translational Sciences, National Institutes of Health, grant 8UL1TR000105. J. Scott McNally-RELATED: Grants: Radiological Society of North America Research Scholar Grant* and University of Utah Intramural Seed Grant. Tina M. Burton-OTHER RELATIONSHIPS: Vascular Neurology Fellow at the National Institutes of Health/National Institute of Neurological Disorders and Stroke, from July 1, 2015, to present. Work related to this submission was performed prior to July 1, 2015. Jennifer J. Majersik—UNRELATED: Grants/Grants Pending: National Institutes of Health/National Institute of Neurological Disorders and Stroke. Dylan V. Miller-UNRELATED: Royalties: Elsevier Publishing; Travel/Accommodations/Meeting Expenses Unrelated to Activities Listed: College of American Pathologists, United States and Canadian Academy of Pathology. *Money paid to the institution.

\section{REFERENCES}

1. Go AS, Mozaffarian D, Roger VL, et al; American Heart Association Statistics Committee and Stroke Statistics Subcommittee. Heart Disease and Stroke Statistics_-2013 Update: a report from the American Heart Association. Circulation 2013;127:e6-e245 CrossRef Medline

2. Petty GW, Brown RD Jr, Whisnant JP, et al. Ischemic stroke subtypes: a population-based study of incidence and risk factors. Stroke 1999;30:2513-16 CrossRef Medline

3. Flaherty ML, Kissela B, Khoury JC, et al. Carotid artery stenosis as a cause of stroke. Neuroepidemiology 2013;40:36-41 CrossRef Medline

4. Lee BI, Nam HS, Heo JH, et al; Yonsei Stroke Team. Yonsei Stroke Registry: analysis of 1,000 patients with acute cerebral infarctions. Cerebrovasc Dis 2001;12:145-51 CrossRef Medline

5. Tsantilas P, Kühnl A, Kallmayer M, et al. Stroke risk in the early period after carotid related symptoms: a systematic review. J Cardiovasc Surg (Torino) 2015;56:845-52 Medline

6. Lovett JK, Coull AJ, Rothwell PM. Early risk of recurrence by subtype of ischemic stroke in population-based incidence studies. Neurology 2004;62:569-73 CrossRef Medline

7. Redfors P, Jood K, Holmegaard L, et al. Stroke subtype predicts outcome in young and middle-aged stroke sufferers. Acta Neurol Scand 2012;126:329-35 CrossRef Medline

8. Adams HP Jr, Bendixen BH, Kappelle LJ, et al. Classification of subtype of acute ischemic stroke: definitions for use in a multicenter clinical trial-TOAST. Trial of Org 10172 in Acute Stroke Treatment. Stroke 1993;24:35-41 CrossRef Medline

9. Hosseini AA, Kandiyil N, Macsweeney ST, et al. Carotid plaque hemorrhage on magnetic resonance imaging strongly predicts recurrent ischemia and stroke. Ann Neurol 2013;73:774-84 CrossRef Medline

10. Gupta A, Baradaran H, Schweitzer AD, et al. Carotid plaque MRI and stroke risk: a systematic review and meta-analysis. Stroke 2013;44: 3071-77 CrossRef Medline

11. Saam T, Hetterich H, Hoffmann V, et al. Meta-analysis and systematic review of the predictive value of carotid plaque hemorrhage on cerebrovascular events by magnetic resonance imaging. J Am Coll Cardiol 2013;62:1081-91 CrossRef Medline

12. Ota H, Yarnykh VL, Ferguson MS, et al. Carotid intraplaque hemorrhage imaging at 3.0-T MR imaging: comparison of the diagnostic performance of three T1-weighted sequences. Radiology 2010;254: 551-63 CrossRef Medline

13. Regoli D, Plante GE, Gobeil F, Jr. Impact of kinins in the treatment of cardiovascular diseases. Pharmacol Ther 2012;135:94-111 CrossRef Medline

14. da Cunha V, Martin-McNulty B, Vincelette J, et al. Angiotensin II induces histomorphologic features of unstable plaque in a murine model of accelerated atherosclerosis. J Vasc Surg 2006;44:364-71 CrossRef Medline

15. Skultetyova D, Filipova S, Riecansky I, et al. The role of angiotensin type 1 receptor in inflammation and endothelial dysfunction. Recent Pat Cardiovasc Drug Discov 2007;2:23-27 Medline

16. Forman JP, Williams JS, Fisher ND. Plasma 25-hydroxyvitamin D and regulation of the renin-angiotensin system in humans. Hypertension 2010;55:1283-88 CrossRef Medline

17. Gupta GK, Agrawal T, Del Core MG, et al. Decreased expression of vitamin $\mathrm{D}$ receptors in neointimal lesions following coronary artery angioplasty in atherosclerotic swine. PLoS One 2012;7:e42789 CrossRef Medline

18. Carrelli AL, Walker MD, Lowe H, et al. Vitamin D deficiency is associated with subclinical carotid atherosclerosis: the Northern Manhattan study. Stroke 2011;42:2240-45 CrossRef Medline

19. Liu JX, Xiang J, Bu RF, et al. Serum 25-hydroxyvitamin D concentration is negatively related to carotid artery intima-media thickness in type 2 diabetic patients[In Chinese]. Zhonghua Xin Xue Guan Bing Za Zhi 2012;40:115-19 Medline

20. Anderson JL, May HT, Horne BD, et al; Intermountain Heart Collaborative (IHC) Study Group. Relation of vitamin D deficiency to cardiovascular risk factors, disease status, and incident events in a general healthcare population. Am J Cardiol 2010;106:963-68 CrossRef Medline

21. Forrest KY, Stuhldreher WL. Prevalence and correlates of vitamin D deficiency in US adults. Nutr Res 2011;31:48-54 CrossRef Medline

22. Hadley JR, Roberts JA, Goodrich KC, et al. Relative RF coil performance in carotid imaging. Magn Reson Imaging 2005;23:629-39 CrossRef Medline

23. Tate Q, Kim SE, Treiman G, et al. Increased vessel depiction of the carotid bifurcation with a specialized 16-channel phased array coil at 3T. Magn Reson Med 2013;69:1486-93 CrossRef Medline

24. Chapman BE, Minalga ES, Brown C, et al. Reducing morphological variability of the cervical carotid artery in serial magnetic resonance imaging using a head and neck immobilization device. $J$ Magn Reson Imaging 2008;28:258-62 CrossRef Medline

25. Zhu DC, Ferguson MS, DeMarco JK. An optimized 3D inversion recovery prepared fast spoiled gradient recalled sequence for carotid plaque hemorrhage imaging at 3.0 T. Magn Reson Imaging 2008;26:1360-66 CrossRef Medline

26. McNally JS, Yoon HC, Kim SE, et al. Carotid MRI detection of intraplaque hemorrhage at 3T and 1.5T. J Neuroimaging 2015;25:390-96 CrossRef Medline

27. North American Symptomatic Carotid Endarterectomy Trial: methods, patient characteristics, and progress. Stroke 1991;22: 711-20 CrossRef Medline 
28. Fox AJ. How to measure carotid stenosis. Radiology 1993;186: 316-18 CrossRef Medline

29. Fox AJ, Eliasziw M, Rothwell PM, et al. Identification, prognosis, and management of patients with carotid artery near occlusion. AJNR Am J Neuroradiol 2005;26:2086-94 Medline

30. Bartlett ES, Walters TD, Symons SP, et al. Quantification of carotid stenosis on CT angiography. AJNR Am J Neuroradiol 2006;27:13-19 Medline

31. U-King-Im JM, Fox AJ, Aviv RI, et al. Characterization of carotid plaque hemorrhage: a CT angiography and MR intraplaque hemorrhage study. Stroke 2010;41:1623-29 CrossRef Medline

32. Menon BK, Singh J, Al-Khataami A, et al; Calgary CTA Study Group. The donut sign on CT angiography: an indicator of reversible intraluminal carotid thrombus? Neuroradiology 2010;52:1055-56 CrossRef Medline

33. Sacco RL, Kasner SE, Broderick JP, et al; American Heart Association Stroke Council, Council on Cardiovascular Surgery and Anesthesia, Council on Cardiovascular Radiology and Intervention, Council on Cardiovascular and Stroke Nursing, Council on Epidemiology and Prevention, Council on Peripheral Vascular Disease, Council on Nutrition, Physical Activity and Metabolism. An updated definition of stroke for the 21st century: a statement for healthcare professionals from the American Heart Association/American Stroke Association. Stroke 2013;44:2064-89 CrossRef Medline

34. McNally JS, Kim SE, Yoon HC, et al. Carotid magnetization-prepared rapid acquisition with gradient-echo signal is associated with acute territorial cerebral ischemic events detected by diffusionweighted MRI. Circ Cardiovasc Imaging 2012;5:376-82 CrossRef Medline

35. Chou MC, Tzeng WS, Chung HW, et al. T2-enhanced tensor diffusion trace-weighted image in the detection of hyper-acute cerebral infarction: comparison with isotropic diffusion-weighted image. Eur J Radiol 2010;74:e89-94 CrossRef Medline

36. Zou GY, Donner A. Extension of the modified Poisson regression model to prospective studies with correlated binary data. Stat Methods Med Res 2013;22:661-70 CrossRef Medline

37. Maldonado G, Greenland S. Simulation study of confounder-selection strategies. Am J Epidemiol 1993;138:923-36 Medline

38. Vittinghoff $\mathrm{E}, \mathrm{McCulloch} \mathrm{CE}$. Relaxing the rule of ten events per variable in logistic and Cox regression. Am J Epidemiol 2007;165: 710-18 CrossRef Medline

39. Norman PE, Powell JT. Vitamin D and cardiovascular disease. Circ Res 2014;114:379-93 CrossRef Medline
40. Wang TJ, Pencina MJ, Booth SL, et al. Vitamin D deficiency and risk of cardiovascular disease. Circulation 2008;117:503-11 CrossRef Medline

41. Brondum-Jacobsen P, Nordestgaard BG, Schnohr P, et al. 25-hydroxyvitamin $\mathrm{D}$ and symptomatic ischemic stroke: an original study and meta-analysis. Ann Neurol 2013;73:38-47 CrossRef Medline

42. Turetsky A, Goddeau RP Jr, Henninger N. Low serum vitamin D is independently associated with larger lesion volumes after ischemic stroke. J Stroke Cerebrovasc Dis 2015;24:1555-63 CrossRef Medline

43. Sato Y, Iwamoto J, Kanoko T, et al. Low-dose vitamin D prevents muscular atrophy and reduces falls and hip fractures in women after stroke: a randomized controlled trial. Cerebrovasc Dis 2005;20: 187-92 CrossRef Medline

44. Yalbuzdag SA, Sarifakioglu B, Afsar SI, et al. Is 25(OH)D associated with cognitive impairment and functional improvement in stroke? A retrospective clinical study. J Stroke Cerebrovasc Dis 2015;24: 1479-86 CrossRef Medline

45. Molinari C, Uberti F, Grossini E, et al. 1 $\alpha$,25-dihydroxycholecalciferol induces nitric oxide production in cultured endothelial cells. Cell Physiol Biochem 2011;27:661-68 CrossRef Medline

46. Dong J, Wong SL, Lau CW, et al. Calcitriol protects renovascular function in hypertension by down-regulating angiotensin II type 1 receptors and reducing oxidative stress. Eur Heart J 2012;33: 2980-90 CrossRef Medline

47. Zhao XQ, Dong L, Hatsukami T, et al. MR imaging of carotid plaque composition during lipid-lowering therapy a prospective assessment of effect and time course. JACC Cardiovasc Imaging 2011;4: 977-86 CrossRef Medline

48. Dong L, Kerwin WS, Chen H, et al. Carotid artery atherosclerosis: effect of intensive lipid therapy on the vasa vasorum-evaluation by using dynamic contrast-enhanced MR imaging. Radiology 2011;260: 224-31 CrossRef Medline

49. Yoshida K, Sadamasa N, Narumi O, et al. Symptomatic low-grade carotid stenosis with intraplaque hemorrhage and expansive arterial remodeling is associated with a high relapse rate refractory to medical treatment. Neurosurgery 2012;70:1143-50; discussion 1150-51 CrossRef Medline

50. Khayznikov M, Kumar A, Wang P, et al. Statin intolerance and vitamin D supplementation. $N$ Am J Med Sci 2015;7:339-40 Medline

51. Atkin AJ, Gorely T, Clemes SA, et al. Methods of measurement in epidemiology: sedentary behaviour. Int J Epidemiol 2012;41: 1460-71 CrossRef Medline 